\title{
BMJ Open The association of dietary quality with colorectal cancer among normal weight, overweight and obese men and women: a prospective longitudinal study in the USA
}

\author{
Rosalie A Torres Stone, ${ }^{1,2}$ Molly E Waring, ${ }^{3}$ Sarah L Cutrona, ${ }^{4}$ Catarina I Kiefe, ${ }^{3}$ \\ Jeroan Allison, ${ }^{3}$ Chyke A Doubeni ${ }^{5}$
}

To cite: Torres Stone RA, Waring ME, Cutrona SL, et al. The association of dietary quality with colorectal cancer among normal weight, overweight and obese men and women: a prospective longitudinal study in the USA. BMJ Open 2017;7:e015619. doi:10.1136/ bmjopen-2016-015619

- Prepublication history for this paper is available online. To view these files please visit the journal online (http://dx.doi org/10.1136/bmjopen-2016015619).

Received 20 December 2016 Revised 18 May 2017 Accepted 25 May 2017

CrossMark

For numbered affiliations see end of article.

Correspondence to

Rosalie A Torres Stone;

rtorresstone@clarku.edu

\section{ABSTRACT}

Objective Lower body mass index (BMI) and higher dietary quality reduce the risk of colorectal cancer (CRC). A full understanding of how these associations vary by sex and weight is lacking.

Methods We used data from the National Institutes of Health - American Association of Retired Persons (NIH)AARP) Diet and Health Study for 398458 persons who were 50-71 years old in 1995-1996 and followed through 2006. Exposures were dietary quality as reflected by the Mediterranean Diet, the Healthy Eating Index-2010 and the Dietary Approaches to Stop Hypertension score, stratified by BMI category. The outcome was CRC diagnosis from cancer registry data. Cox regression models were adjusted for disease risk factors.

Results Over a mean duration of 123 months of followup, there were 6515 new diagnoses of CRC (1953 among the normal weight, 2924 among the overweight and 1638 among the obese; 4483 among men and 2032 among women). For normal weight and overweight men, we found a strong dose-response pattern for the association of increasing quintile of dietary quality with decreasing risk of CRC; this pattern was observed for obese men as well, but less consistently across the three measures of dietary quality. The findings were of smaller magnitude and less consistent for women but still suggesting associations of similar direction.

Conclusion We observed that increased dietary quality was associated with lower risk of incident CRC up to 10 years later for men regardless of baseline weight category.

\section{INTRODUCTION}

Colorectal cancer (CRC) is the third leading cause of cancer-related deaths in the USA, resulting in an estimated of more than 49000 deaths in 2016. ${ }^{1}$ Modifiable risk factors such as excess body weight and unhealthy behaviours (sedentary lifestyles, unhealthy dietary patterns and smoking) increase the risk of CRC. $^{2-15}$ Most CRCs are preventable through screening, detection and removal of precancerous lesions or by engaging in healthful
Strengths and limitations of this study

- To our knowledge, this is the first study to examine the potential benefits of healthy eating patterns in reducing colorectal cancer risk among men and women who are at normal weight, overweight and obese adults.

- Key strengths of this study include a large US national study of 398458 middle-aged and older adults with a prospective design, use of three indices of dietary patterns to assess association of high-quality diet with outcomes rather than individual dietary components, careful ascertainment of dietary exposures using Food Frequency Questionnaire and cancer outcome and the long follow-up interval.

- Our study has some limitations. We did not have information on family history of colorectal cancer, although the impact of family history is likely small given the age of the cohort. Dietary intake was self-reported and assessed using a single baseline measurement. Therefore, there is a potential for non-differential classification of dietary exposures, and we could not examine changes in dietary intake over time. Our study population was relatively homogeneous with upper to middle class US Americans in urban centres, and over 90\% of the sample was non-Hispanic white, limiting generalisability to diverse population groups.

behaviours. ${ }^{1617}$ More specifically, it has been estimated that up to $70 \%$ of CRCs could be avoided by risk factor modification. ${ }^{18}$

Obesity is a particularly concerning risk factor, as $37 \%$ of US adults are obese. ${ }^{19} \mathrm{~A}$ recent meta-analysis found a 30\% higher risk of colon cancer in men and a $12 \%$ higher risk in women for every $5 \mathrm{~kg} / \mathrm{m}^{2}$ increase in body mass index (BMI). ${ }^{9}$ Another meta-analysis found that obese adults were at roughly $20 \%$ greater risk of developing CRC compared with 
those of normal weight, and the risk of CRC increased $7 \%$ for every $2 \mathrm{~kg} / \mathrm{m}^{2}$ higher BMI. ${ }^{10}$

Like obesity, diet is estimated to be one of the most important modifiable risk factors for CRC. ${ }^{13-15}$ A dietary pattern that is rich in whole grains, vegetables, fruit, fish, legumes and nuts and low in red and processed meat and alcohol has been linked to a substantial reduction in the risk of CRC. ${ }^{2-7} 1314$ Therefore, the WHO recommends improving dietary quality by increasing consumption of fruit and vegetables, as well as legumes, whole grains and nuts. ${ }^{20}$ These recommendations are similar to those studied in the Dietary Approaches to Stop Hypertension trial $^{2122}$ and are also similar to recommendations found in the Mediterranean Diet examined in the Seven Countries Study. ${ }^{13} 23$

Despite the potential benefits of a healthy BMI, many overweight and obese adults are not motivated or able to lose weight, ${ }^{24}$ raising important questions. In the absence of weight loss, can a healthy diet still reduce CRC risk among overweight or obese adults? Likewise, because diet is emphasised as a means for weight loss, those who may be of normal weight may also lack the motivation to engage in health eating. These considerations raise unanswered questions about how the association of health eating patterns varies by weight categories. Therefore, our study examined the association between dietary quality and the risk of CRC and studied the variation in this association among normal weight, overweight and obese adults. Because dietary patterns have been observed to be different for men and women, analyses were stratified by gender. $^{13}$

\section{METHODS}

We used data from the National Institutes of Health-American Association of Retired Persons) Diet and Health Study (NIH-AARP). The NIH-AARP cohort was established in 1995-1996. AARP members who were contacted returned questionnaires eliciting information on demographic and anthropometric characteristics, dietary intake and health-related behaviours. The initial response rate was $18 \%$. Eligible participants were $50-71$ years old and resided in six US states (California, Florida, Louisiana, New Jersey, North Carolina and Pennsylvania) and two metropolitan areas (Atlanta, Georgia, and Detroit, Michigan).

\section{Outcome}

The outcome for this analysis was diagnosis with incident adenocarcinoma of the colon/rectum ascertained from tumour registries through 31 December 2006. Cancer diagnosis in participants was determined through probabilistic linkage with eight state cancer registries. A validation study found that this approach captured approximately $90 \%$ of all cancers. ${ }^{25}$ Cancer type and histological characteristics were obtained from tumour registry data using International Classification of Diseases - Oncology codes $(8000,8010,8020,8140-43$,
8210-8211, 8221, 8255, 8261-3, 8480-1, 8490, 8510 and 8574).

\section{Determinants}

The main determinants for this analysis were three indices of dietary quality. At baseline in 1995-1996, dietary intake during the past 12 months were assessed using a 124-item Food Frequency Questionnaire. The NIH-AARP Food Frequency Questionnaire was previously validated against 24 hours dietary recall in this cohort. ${ }^{25}$ The Diet History Questionnaire has been calibrated, ${ }^{25}{ }^{26}$ and further validation was performed by using two 24 hours recalls within a subset of the NIH-AARP Diet and Health Study. ${ }^{27}$ By using the guidance-based food group equivalents and other nutrient variables, we calculated component and index scores for the Healthy Eating Index-2010 (HEI2010), ${ }^{28}$ the Mediterranean Diet Score ${ }^{29}$ and the Dietary Approaches to Stop Hypertension (DASH), ${ }^{29}$ according to algorithms described by Reedy et $a l^{30}$

The Mediterranean Diet Score ranges from 0 to 9 with higher scores corresponding to diets more consistent with a Mediterranean diet. ${ }^{1329} 31$ One point each is given for: intake at or greater than the sex-specific median for vegetables, fruit, nuts, legumes, fish and whole grains, and intake less than the sex-specific median for the monounsaturated: saturated fat ratio and red and processed meat. Alcohol intake was scored by predetermined cut points for moderate intake (men: 10-25 g per day, women: 5-15 $\mathrm{g}$ per day ${ }^{13}$; participants with moderate alcohol intake received 1point; other intakes (none, occasional and excessive) received 0 points.

The HEI-2010 was developed for measuring dietary quality based on federal guidelines. ${ }^{28}$ It awards points based on the adequacy of intake in nine categories (total vegetables, greens and beans, total fruit, whole fruit, whole grains, dairy, total protein foods, seafood and plant proteins and fatty acids) and moderation of intake in three categories (sodium, refined grains and empty calories). The HEI-2010 ranges from 0 to 100 with higher scores indicating better dietary quality.

DASH scores capture the diet tested in two DASH randomised controlled feeding trials, ${ }^{21} 32$ which examined the role of dietary patterns on blood pressure. Several versions of the DASH score exist, and we used the one most commonly found in the literature with US populations. ${ }^{29}$ To derive the score for the DASH Diet, intake was classified into quintiles for the following categories: fruits, vegetables, nuts and legumes, whole grains, low-fat dairy (higher intake indicated by higher quintile) and sodium, red and processed meats, and sweetened beverages (higher intake indicated by lower quintiles).$^{30}$ Based on these eight categories, the DASH Score ranged from 8 to 40 , with higher scores indicating better dietary quality. DASH Score was energy adjusted.

BMI was calculated from height and weight self-reported at baseline and categorised based on WHO criteria (normal: $18.5-<25 \mathrm{~kg} / \mathrm{m}^{2}$, overweight: $25-<30 \mathrm{~kg} / \mathrm{m}^{2}$ and obese: $\geq 30 \mathrm{~kg} / \mathrm{m}^{2}$ ). 


\section{Covariates}

Characteristics self-reported at baseline included gender, age (50-54 years, 55-59 years, $60-64$ years, $65-69$ years and $\geq 70$ years), educational level (high school or less, some college or college degree) and race/ethnicity (non-Hispanic white, non-Hispanic black, Hispanic, Asian/Pacific Islander and American Indian/Alaskan Native). Other risk factors for CRC included: smoking status (never smoked, former smoker and current smoker) and physical activity. Participants were asked how often (in the previous 12 months) they engaged in physical activity that lasted $\geq 20 \mathrm{~min}$ and caused increases in breathing or heart rate, or made the participant sweat (never, rarely, 1-3 times per month, 1-2 times per week, 3-4 times per week and $\geq 5$ more times per week).

\section{Construction of the Analytic Sample}

Of the 566398 adults enrolled in the Diet-AARP Health Study, we excluded those who: (1) completed questionnaires by proxy $(\mathrm{n}=15760)$; (2) reported a history of end-stage renal disease (1299); (3) reported a history of cancer (8902) or had registry confirmed prevalent cancer (50 591); (4) reported a history of colonic or rectal polyps (57 179); (5) reported any first-degree relatives with colon cancer (50 552); (6) were underweight (BMI $<18.5 \mathrm{~kg}$ / $\mathrm{m}^{2}$ ) (5912); (7) were missing height or weight (13 944); or (8) reported implausibly high or low energy intake based on Box-Cox transformation procedures designed for this dataset $(n=3534),{ }^{27}$ resulting in an analytic sample of 398458 adults.

\section{Statistical Analysis}

Univariate and summary characteristics were examined for all variables. $\chi^{2}$ tests were used to compare characteristics of participants who did and did not develop CRC over the follow-up period for categorical variables, and the analysis of variance was used for continuous variables. Bivariate analyses also examined the association of each composite dietary measure and several sets of food groups with the incidence of CRC. Linear regression models characterised the association of participant characteristics with dietary adherence, treating the dietary measures as continuous. Based on known risk factors for CRC, covariates in all models included age, gender, race/ ethnicity, education, smoking status, physical activity and weight category. All models were also adjusted for energy intake.

Cox regression with duration of observation as the underlying time metric was used to calculate the hazard of developing CRC for a series of multivariable models. All models entered the dietary measures as quintiles and included adjustment for age, race/ethnicity, education, smoking, physical activity and energy intake. The first set of models were based on stratified subsamples, being estimated separately for each gender-weight category and each dietary measure. A second set of Cox regression models was also created across all weight categories that included interaction terms for weight category and dietary adherence. From this second set of models, we predicted the probability of incident CRC at 10 years for each level of dietary quality and weight by raising the baseline hazard at 10 years to the power of the exponentiated linear predictor. CIs for the predicted probabilities were constructed with the delta method for approximation of complex variance estimates using Taylor linearisation. ${ }^{33}$ Statistical 'trend' tests were performed with the postregression orthogonal polynomial contrast function of Stata V.14.2. We found no evidence to suggest that proportional hazards assumptions were violated. ${ }^{34}$ All analyses were performed with Stata V.14.2.

\section{RESULTS}

At baseline, most participants were $\geq 60$ years old $(61 \%)$ and non-Hispanic white $(91 \%) ; 59 \%$ were men (Table 1). table 1).

About $35 \%$ of the sample were normal weight, $43 \%$ were overweight and $22 \%$ were obese. Mean (SD; range) scores for dietary quality were $4.2(1.8 ; 0-9)$ for the Mediterranean Diet, $65.9(10.7 ; 18.2-98.4)$ for the HEI-2010 and $23.8(4.1 ; 8-37)$ for the DASH Diet.

Over a mean follow-up duration of 123 months, 6515 participants $(1.64 \%)$ were diagnosed with CRC. There were 6515 new diagnoses of CRC (1953 among the normal weight, 2924 among the overweight and 1638 among the obese; 4483 among men and 2032 among women). Of all new diagnoses, $9.7 \%$ were stage $0 ; 38.4 \%$ were stage $1 ; 14.0 \%$ were stage $2 ; 22.7 \%$ were stage 3 ; and $15.3 \%$ were stage 4 . The percent of those diagnosed with CRC increased moving across BMI categories from normal to overweight to obese $(1.4 \%, 1.7 \%, 1.9 \%$; $\mathrm{p}$ value from log-rank trend test $<0.0001)$.

From bivariate analyses, older age, being male, having lower levels of physical activity, smoking, having less education and being overweight or obese were associated with an increased risk of CRC $(\mathrm{p}<0.001)$ (Table 1) table 1$)$. Compared with non-Hispanic whites, the incidence of CRC was higher for non-Hispanic blacks and lower for Asians/Pacific Islanders $(p=0.031)$. Those who developed CRC had lower scores for dietary adherence and consumed more red and processed meats, less whole grains, less dark green vegetables and less fruits.

Based on an overall multivariable model for the entire study population, the hazard of incident CRC diagnosis was $32 \%$ less for women compared with men (adjusted OR (aOR); 95\% CI 0.68; 0.64-0.73). Compared with those who had normal weight, the hazard of incident CRC diagnosis was $13 \%$ greater for those who were overweight (aOR; 95\% CI 1.13; 1.05-1.21) and 30\% greater for those who were obese (aOR; 95\% CI 1.30; 1.20-1.40).

Results from the linear regression models predicting dietary adherence and the measures of dietary quality are presented in table 2. We found 'dose-response' associations for older age, higher education and more frequent physical activity with better scores for each dietary measure. Women had better adherence for all three 
Table 1 Baseline characteristics of sample by subsequent diagnosis of colorectal cancer over 10 years of follow-up, $\mathrm{NIH}-$ AARP Diet and Health Study, 1995-2006

\begin{tabular}{|c|c|c|c|c|}
\hline & Overall & $\begin{array}{l}\text { Did not develop } \\
\text { colorectal cancer }\end{array}$ & $\begin{array}{l}\text { Developed colorectal } \\
\text { cancer }\end{array}$ & p Value \\
\hline $\mathrm{N}$ & 398458 & 391943 & 6515 & \\
\hline$<55$ & 17.28 & 17.42 & 7.97 & \multirow[t]{3}{*}{$<0.001$} \\
\hline $55-59$ & 22.04 & 22.15 & 15.25 & \\
\hline$>69$ & 4.06 & 4.03 & 5.99 & \\
\hline \multicolumn{5}{|l|}{ Gender } \\
\hline Female, \% & 40.60 & 40.76 & 31.19 & $<0.001$ \\
\hline \multicolumn{5}{|l|}{ Race/ethnicity, \% } \\
\hline Asian/Pacific Islander & 1.42 & 1.43 & 1.06 & \multirow{2}{*}{0.031} \\
\hline American Indian/Alaska Native & 0.29 & 0.29 & 0.30 & \\
\hline \multicolumn{5}{|l|}{ Education, \% } \\
\hline High school & 26.38 & 26.31 & 30.40 & \multirow[t]{3}{*}{$<0.001$} \\
\hline Some college & 34.24 & 34.23 & 34.86 & \\
\hline College degree & 39.38 & 39.45 & 34.74 & \\
\hline \multicolumn{5}{|l|}{ Smoking status, \% } \\
\hline Never & 37.00 & 37.11 & 30.71 & \multirow[t]{2}{*}{$<0.001$} \\
\hline Former & 50.60 & 50.50 & 56.68 & \\
\hline
\end{tabular}

Physical activity ( $\geq 20 \mathrm{~min}$ in past 12 months), $\%$

\begin{tabular}{|c|c|c|c|c|}
\hline Never & 4.41 & 4.40 & 5.32 & $<0.001$ \\
\hline Rarely & 13.63 & 13.61 & 15.03 & \\
\hline 1-2 times/month & 13.74 & 13.74 & 13.93 & \\
\hline 2-4 times/week & 26.99 & 27.01 & 25.99 & \\
\hline 3-5 times/week & 19.45 & 19.47 & 18.23 & \\
\hline Overweight & 42.81 & 42.77 & 44.88 & \\
\hline Obese & 22.10 & 22.05 & 25.14 & \\
\hline \multicolumn{5}{|l|}{ Dietary scores (mean $\pm S D$ ) } \\
\hline Mediterranean Diet & 4.20 & 4.20 & 4.06 & $<0.001$ \\
\hline \multicolumn{5}{|l|}{ Food consumption } \\
\hline Whole grain oz./day & 0.997 & 0.998 & 0.962 & 0.001 \\
\hline Dark green vegetable cups/day & 0.242 & 0.242 & 0.221 & $<0.001$ \\
\hline Dry beans and peas cups/day & 0.101 & 0.101 & 0.100 & 0.472 \\
\hline Fruit (excluding juice) cups/day & 1.264 & 1.265 & 1.223 & 0.003 \\
\hline Chicken and poultry oz./day & 0.968 & 0.968 & 0.932 & 0.003 \\
\hline Fish high in omega-3 oz./day & 0.169 & 0.169 & 0.165 & 0.051 \\
\hline Franks, sausages, luncheon meats oz./day & 0.564 & 0.563 & 0.628 & $<0.001$ \\
\hline
\end{tabular}


Table 1 Continued

\begin{tabular}{lllll}
\hline & Overall & $\begin{array}{l}\text { Did not develop } \\
\text { colorectal cancer }\end{array}$ & \multicolumn{2}{c}{$\begin{array}{l}\text { Developed colorectal } \\
\text { cancer }\end{array}$} \\
\hline Beef, pork, veal, lamb oz./day & 1.625 & 1.622 & 1.774 & $\mathbf{p}$ Value \\
\hline
\end{tabular}

Weight status was based on BMI (normal weight: $18.5-<25 \mathrm{~kg} / \mathrm{m}^{2}$; overweight: $25-<30 \mathrm{~kg} / \mathrm{m}^{2}$; obese: $\geq 30 \mathrm{~kg} / \mathrm{m}^{2}$ ).

Food consumption based on equivalent values from MyPyramid Equivalents Database (MPED).

BMI, body mass index.

dietary patterns. Those who were non-Hispanic black had better dietary scores for the Mediterranean Diet and the Health Eating Index but had lower DASH scores. Asians/
Pacific Islanders had slightly lower scores on all three dietary measures. Separate models for men and women revealed no important differences (data not shown).

Table 2 Multivariable association of participant characteristics with dietary patterns, NIH-AARP Diet and Health Study, 19962006

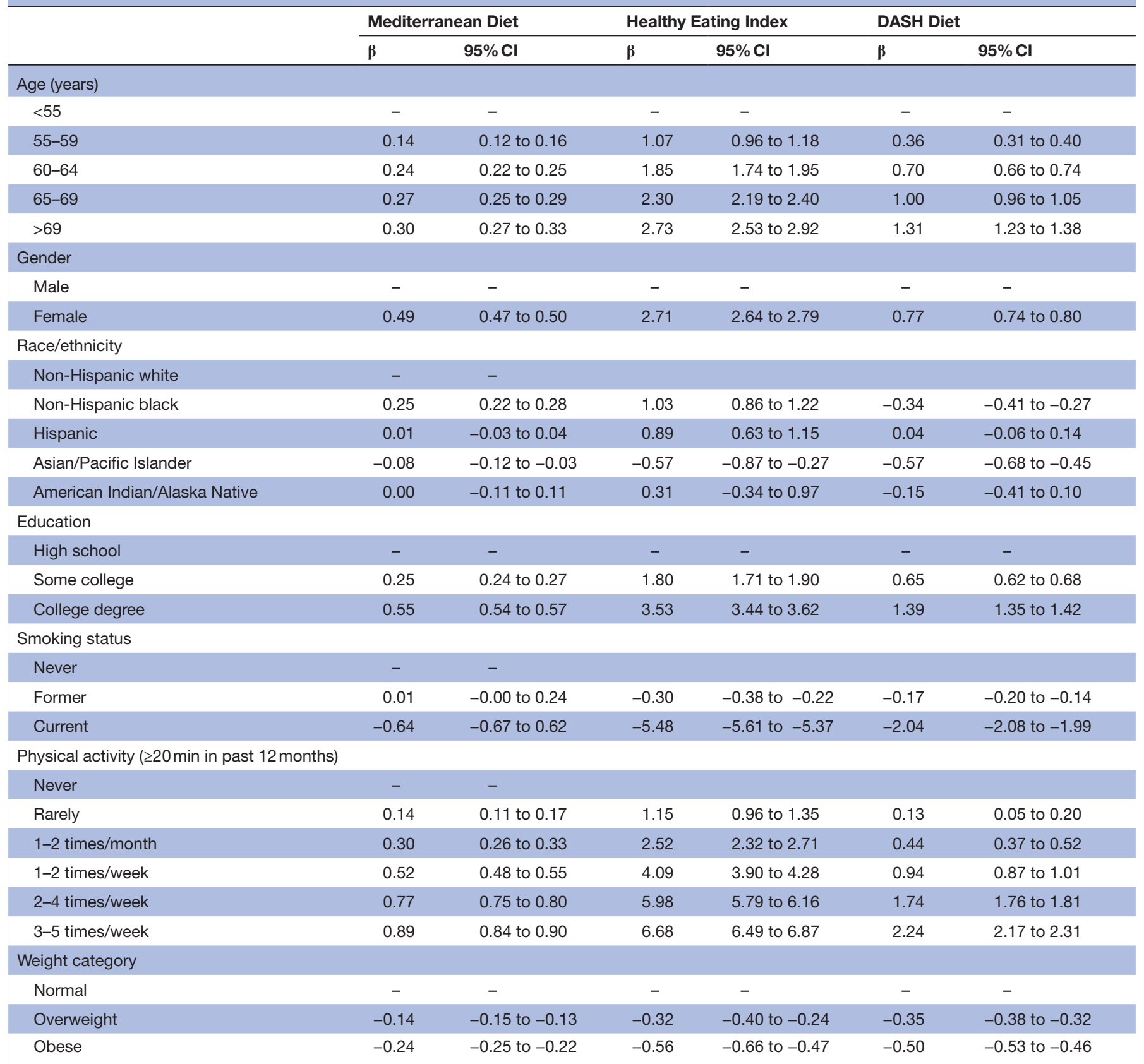

From separate linear regression models for each dietary measure, with adjustment for energy intake. Weight categories were based on BMI (normal: $18.5-<25 \mathrm{~kg} / \mathrm{m}^{2}$; overweight: $25-<30 \mathrm{~kg} / \mathrm{m}^{2}$; obese: $\geq 30 \mathrm{~kg} / \mathrm{m}^{2}$ ). 
The first set of multivariable models were stratified by weight category and examined the association of incident CRC by quintile of dietary score. Based on these models, which included adjustment for age, gender, race/ ethnicity, smoking, physical activity and energy intake, increasing dietary quality was consistently associated with decreasing hazard of incident CRC for men of normal weight or were overweight (table 3a). For obese men, the same general patterns were apparent, but the statistical significance across quintiles of dietary quality was more marginal than for the other two BMI categories. Smaller and more inconsistent associations, although generally in the same direction, were found for women of all three weight categories (table 3b).

Based on the multivariable model Cox regression models, we predicted the incidence of new CRC at 10 years separately for men (table 4a) and women (table 4b). We found almost no statistical significance for the interaction of dietary measures with weight category for both men and women, providing no basis for refuting the hypothesis that the association of diet with incidence CRC differs by weight category. As shown in table 4 a, we found statistically significant linear trends for men who were of normal weight and who were overweight, suggesting a gradient effect for increasing dietary quality with decreasing incidence of CRC at 10 years. Likewise, among obese men, we found generally similar trends, which were of more marginal statistical significance. Consistent with the previously described HRs, the findings were also more mixed for women (table $4 \mathrm{~b}$ ). For both men and women, the absolute predicted rates of CRC were consistently less than $2.5 \%$.

\section{DISCUSSION}

In this large national study of nearly 400000 of middleaged and older adults, we found that baseline high-quality diets as measured by three diet quality indices (Mediterranean Diet Score, the HEI-2010 and the DASH Score) were each associated with lower risk of CRC over a subsequent 10-year period among men who were of normal weight and overweight in a generally consistent 'dose-response' effect. Trends were less consistent and of smaller

Table 3a HRs and 95\% Cls for incidence of colorectal cancer by baseline dietary pattern and weight category, NIH-AARP Diet and Health Study for Men, 1996-2006 ( $n=182762)$

\begin{tabular}{|c|c|c|c|c|c|c|}
\hline \multirow[b]{2}{*}{ Dietary score } & \multicolumn{2}{|c|}{ Normal weight } & \multicolumn{2}{|c|}{ Overweight } & \multicolumn{2}{|l|}{ Obese } \\
\hline & HR & $95 \% \mathrm{Cl}$ & HR & $95 \% \mathrm{Cl}$ & HR & $95 \% \mathrm{Cl}$ \\
\hline \multicolumn{7}{|c|}{ Mediterranean Diet Quintiles } \\
\hline 2 & 0.79 & 0.66 to 0.96 & 0.83 & 0.73 to 0.95 & 0.97 & 0.80 to 1.17 \\
\hline 3 & 0.66 & 0.54 to 0.82 & 0.91 & 0.79 to 1.04 & 0.99 & 0.82 to 1.21 \\
\hline 5 & 0.65 & 0.51 to 0.83 & 0.73 & 0.60 to 0.88 & 0.79 & 0.59 to 1.08 \\
\hline $\mathrm{p}$ for trend & 0.0004 & & 0.0013 & & 0.0508 & \\
\hline \multicolumn{7}{|c|}{ Healthy Eating Index Quintiles } \\
\hline 1 & - & - & - & - & - & - \\
\hline 5 & 0.67 & 0.54 to 0.84 & 0.63 & 0.53 to 0.74 & 0.76 & 0.60 to 0.99 \\
\hline $\mathrm{p}$ for trend & 0.0001 & & $<0.0001$ & & 0.0394 & \\
\hline \multicolumn{7}{|l|}{ DASH Quintiles } \\
\hline 1 & - & - & - & - & - & - \\
\hline 2 & 0.91 & 0.08 to 1.11 & 0.82 & 0.72 to 0.94 & 0.71 & 0.59 to 0.87 \\
\hline 3 & 0.79 & 0.64 to 0.99 & 0.73 & 0.63 to 0.85 & 0.78 & 0.63 to 0.96 \\
\hline 4 & 0.83 & 0.66 to 1.04 & 0.69 & 0.59 to 0.82 & 0.80 & 0.64 to 1.00 \\
\hline 5 & 0.67 & 0.54 to 0.84 & 0.70 & 0.60 to 0.82 & 0.75 & 0.60 to 0.94 \\
\hline$p$ for trend & 0.0005 & & $<0.0001$ & & 0.0801 & \\
\hline
\end{tabular}

Cox proportional hazard models adjusted for age, gender, race/ethnicity, education, smoking, physical activity and energy intake. Separate models were developed for each dietary pattern and weight category. Dietary categories (low and high) are based on tertiles of native score. The lowest tertile is the reference group. Weight categories were based on BMI (normal: $18.5-<25 \mathrm{~kg} / \mathrm{m}^{2} ;$ overweight: $25-<30 \mathrm{~kg} / \mathrm{m}^{2}$; obese: $\geq 30 \mathrm{~kg} / \mathrm{m}^{2}$ ). 
Table 3b HRs and 95\% Cls for incidence of colorectal cancer by baseline dietary pattern and weight category, NIH-AARP Diet and Health Study for Women, 1996-2006 ( $n=125281)$

\begin{tabular}{|c|c|c|c|c|c|c|}
\hline \multicolumn{3}{|c|}{ Normal weight } & \multicolumn{2}{|c|}{ Overweight } & \multicolumn{2}{|l|}{ Obese } \\
\hline Dietary score & HR & $95 \% \mathrm{Cl}$ & HR & $95 \% \mathrm{Cl}$ & HR & $95 \% \mathrm{Cl}$ \\
\hline \multicolumn{7}{|c|}{ Mediterranean Diet Quintiles } \\
\hline 2 & 0.95 & 0.76 to 1.20 & 1.09 & 0.86 to 1.38 & 1.35 & 1.04 to 1.74 \\
\hline 3 & 0.88 & 0.69 to 1.12 & 1.00 & 0.78 to 1.30 & 0.86 & 0.64 to 1.16 \\
\hline 5 & 1.02 & 0.75 to 1.37 & 0.99 & 0.68 to 1.41 & 0.95 & 0.63 to 1.43 \\
\hline $\mathrm{p}$ for trend & 0.9384 & & 0.4318 & & 0.2633 & \\
\hline
\end{tabular}

Healthy Eating Index Quintiles

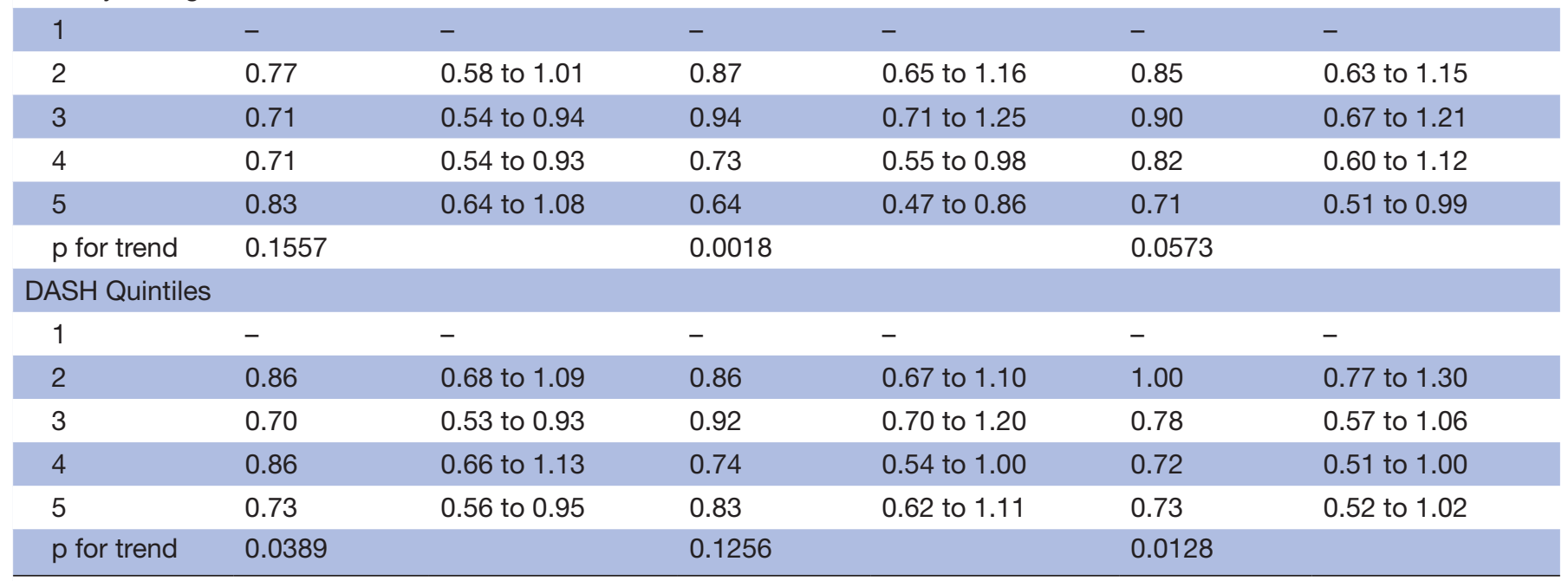

Cox proportional hazard models adjusted for age, gender, race/ethnicity, education, smoking, physical activity and energy intake. Separate models were developed for each dietary pattern and weight category. Dietary adherence categories are based on lowest and highest tertiles. Weight categories were based on BMI (normal: $18.5-<25 \mathrm{~kg} / \mathrm{m}^{2}$; overweight: $25-<30 \mathrm{~kg} / \mathrm{m}^{2}$; obese: $\geq 30 \mathrm{~kg} / \mathrm{m}^{2}$ ).

BMI, body mass index.

magnitude among men who were obese and women in all three weight categories.

Although previous studies have not examined differences according to baseline weight status, our findings are consistent with other studies demonstrating that higher dietary quality is associated with reduced risk of colorectal adenoma in general. ${ }^{13}$ For example, a recent narrative review of publications using the Nurses' Health Study (1976-2016) identified red and processed meat, alcohol, smoking and obesity as factors that increase the risk of CRC. ${ }^{15}$ Likewise, an ecological study suggested that $76 \%$ of the intercountry variation in CRC incidence was explained by meat, fish and olive oil intake, with olive oil intake being associated with reduced risk. ${ }^{2}$

A review of epidemiological studies investigating the associations between dietary patterns including the DASH, the Mediterranean Diet and the Healthy Eating Index has also shown a consistently reduced risk of colorectal adenoma and cancer incidence of higher scores on all of the dietary indexes for men but was less conclusive for women. ${ }^{13} 35$ Another large prospective examination of four established DASH indexes found that greater compliance with the DASH dietary pattern was associated with a reduced risk of CRC for both men and women. ${ }^{36}$ This consistency across the three dietary patterns is not surprising because each of these dietary approaches is built on a similar foundation of fresh fruits and vegetables, whole grains and low saturated fat.

There are physiological mechanisms through which diet may be associated with a reduced risk of CRC and through which this association may differ for men and for women. For example, studies focused on individual nutrients suggest that olive oil may exert a reduced risk of CRC by influencing secondary bile acid patterns in the colon. This may in turn affect polyamine metabolism in colonic enterocytes, reducing progression from normal mucosa to adenoma and carcinoma. ${ }^{3}$ Fibre intake may reduce the contact between carcinogens and the lining of the colon/rectum and increase stool bulk, which dilutes faecal carcinogens and decreases transit time. ${ }^{27}$ Red and processed meat may exert a carcinogenic effect due to heme iron, N-nitro compounds and heterocyclic amines generated during cooking at high temperatures as well as a proneoplastic effect due to increased adiposity 
Table 4a Probability and $95 \% \mathrm{Cl}$ of colorectal cancer at 10 years by baseline dietary pattern and weight category, NIH-AARP Diet and Health Study for Men, 1996-2006 ( $n=182762)$

\begin{tabular}{|c|c|c|c|c|c|c|}
\hline \multirow[b]{2}{*}{ Dietary score } & \multicolumn{2}{|c|}{$\begin{array}{l}\text { Mediterranean } \\
\text { Diet }\end{array}$} & \multicolumn{2}{|c|}{ Healthy Eating Index } & \multicolumn{2}{|l|}{ DASH } \\
\hline & Probability & $95 \% \mathrm{Cl}$ & Probability & $95 \% \mathrm{Cl}$ & Probability & $95 \% \mathrm{Cl}$ \\
\hline \multicolumn{7}{|c|}{ Normal weight } \\
\hline Quintile 1 & 0.019 & 0.011 to 0.028 & 0.019 & 0.011 to 0.028 & 0.019 & 0.010 to 0.027 \\
\hline Quintile 2 & 0.015 & 0.008 to 0.003 & 0.017 & 0.009 to 0.025 & 0.017 & 0.009 to 0.025 \\
\hline Quintile 3 & 0.013 & 0.007 to 0.019 & 0.015 & 0.008 to 0.022 & 0.015 & 0.007 to 0.022 \\
\hline Quintile 4 & 0.013 & 0.007 to 0.019 & 0.013 & 0.007 to 0.019 & 0.015 & 0.008 to 0.022 \\
\hline Quintile 5 & 0.012 & 0.006 to 0.019 & 0.012 & 0.006 to 0.018 & 0.012 & 0.006 to 0.018 \\
\hline $\mathrm{p}$ for trend & 0.0002 & & $<0.0001$ & & 0.0001 & \\
\hline \multicolumn{7}{|c|}{ Overweight } \\
\hline Quintile 1 & 0.019 & 0.011 to 0.028 & 0.022 & 0.011 to 0.032 & 0.021 & 0.011 to 0.031 \\
\hline Quintile 2 & 0.016 & 0.009 to 0.024 & 0.017 & 0.009 to 0.025 & 0.018 & 0.010 to 0.026 \\
\hline Quintile 3 & 0.018 & 0.010 to 0.027 & 0.016 & 0.008 to 0.023 & 0.016 & 0.008 to 0.024 \\
\hline Quintile 4 & 0.016 & 0.0090 .023 & 0.018 & 0.009 to 0.026 & 0.016 & 0.008 to 0.023 \\
\hline Quintile 5 & 0.015 & 0.008 to 0.022 & 0.014 & 0.007 to 0.020 & 0.016 & 0.008 to 0.023 \\
\hline $\mathrm{p}$ for trend & 0.0017 & & $<0.0001$ & & $<0.0001$ & \\
\hline \multicolumn{7}{|c|}{ Obese } \\
\hline Quintile 1 & 0.021 & 0.011 to 0.030 & 0.022 & 0.012 to 0.032 & 0.024 & 0.012 to 0.035 \\
\hline Quintile 2 & 0.020 & 0.011 to 0.030 & 0.021 & 0.011 to 0.031 & 0.017 & 0.009 to 0.026 \\
\hline Quintile 3 & 0.021 & 0.011 to 0.031 & 0.019 & 0.009 to 0.027 & 0.019 & 0.010 to 0.029 \\
\hline Quintile 4 & 0.017 & 0.009 to 0.026 & 0.020 & 0.011 to 0.029 & 0.020 & 0.010 to 0.030 \\
\hline Quintile 5 & 0.017 & 0.008 to 0.026 & 0.017 & 0.009 to 0.026 & 0.019 & 0.010 to 0.028 \\
\hline $\mathrm{p}$ for trend & 0.0212 & & 0.0304 & & 0.0502 & \\
\hline
\end{tabular}

Probabilities are based on a Cox model that adjusts for age, gender, race/ethnicity, education, smoking, physical activity and energy intake. Models include interaction terms for baseline dietary scores and weight category. Separate models were developed for each dietary pattern. Weight categories were based on BMI (normal: $18.5-<25 \mathrm{~kg} / \mathrm{m}^{2}$; overweight: $25-<30 \mathrm{~kg} / \mathrm{m}^{2}$; obese: $\geq 30 \mathrm{~kg} / \mathrm{m}^{2}$ ).

$\mathrm{p}$ Values for interaction terms for quintiles of Mediterranean diet and weight category are: Q2-overweight, 0.626; Q2-obese, 0.159; Q3overweight, 0.008; Q3-obese, 0.006; Q4-overweight, 0.250; Q4-obsese, 0.408; Q5-overweight, 0.367; Q5-obese, 0.366. p Values for interaction terms for quintiles of Healthy Eating Index and weight category are: Q2-overweight, 0.227; Q2-obese, 0.961; Q3-overweight, 0.411; Q3-obese, 0.974; Q4-overweight, 0.304; Q4-obsese, 0.164; Q5-overweight, 0.726; Q5-obese, 0.381. $p$ Values for interaction terms for quintiles of DASH and weight category are: Q2-overweight, 0.486; Q2-obese, 0.090; Q3-overweight, 0.733; Q3-obese, 0.974; Q4-overweight, 0.344; Q4-obsese, 0.920; Q5-overweight, 0.482; Q5-obese, 0.411.

BMI, body mass index.

and insulin. Other studies suggest that dietary patterns that include a high consumption of high saturated fatty acid intake may increase CRC risk via their effects on serum insulin concentrations and on the bioavailability of insulin-like growth factor-I. ${ }^{37}$ Whole grain intake has been associated with decreased fasting insulin level and improved insulin sensitivity. ${ }^{738}$

The differential response of dietary intake to risk of CRC incidence by sex in our study could be explained by differences in the aetiology of CRC between men and women. ${ }^{13}$ Studies have indicated that women are more likely to develop proximal CRC compared with men. ${ }^{39}$ Because proximal and distal CRC appear to arise from different pathways, it is possible that the response to dietary intake varies by proximal and distal location type. ${ }^{39}$ Hormonal factors may also be responsible for sex differences CRC aetiology. Studies of postmenopausal hormone therapy and CRC report a reduction in risk of colon cancer and a decrease in the risk of rectal cancer for postmenopausal women who had ever taken hormone therapy compared with women who never used hormones. The CRC risk reduction appears to be stronger for current and longterm hormone users. ${ }^{40} 41$

The association was of borderline significance and inconsistent across the three dietary measures for obese men and women. It is plausible that the beneficial effects of a healthy diet are attenuated by the inflammatory, hormonal and other metabolic changes induced by obesity that promote colorectal carcinogenesis. ${ }^{42}$ For example, the gut microbiome that provides important metabolic capabilities is responsive to alterations of $\operatorname{diet}^{43}$ and has been shown in obese people to be different from, and less diverse than, those of the non-obese people. ${ }^{44}$ 
Table 4b Probability and $95 \% \mathrm{Cl}$ of colorectal cancer at 10 years by baseline dietary pattern and weight category, NIH-AARP Diet and Health Study for Women, 1996-2006 ( $n=125281)$

\begin{tabular}{|c|c|c|c|c|c|c|}
\hline \multirow[b]{2}{*}{ Dietary score } & \multicolumn{2}{|c|}{$\begin{array}{l}\text { Mediterranean } \\
\text { Diet }\end{array}$} & \multicolumn{2}{|c|}{ Healthy Eating Index } & \multicolumn{2}{|c|}{$\begin{array}{l}\text { Dietary Approaches to Stop } \\
\text { Hypertension }\end{array}$} \\
\hline & Probability & $95 \% \mathrm{Cl}$ & Probability & $95 \% \mathrm{Cl}$ & Probability & $95 \% \mathrm{Cl}$ \\
\hline \multicolumn{7}{|c|}{ Normal weight } \\
\hline Quintile 1 & 0.011 & 0.001 to 0.021 & 0.013 & 0.001 to 0.025 & 0.012 & 0.001 to 0.023 \\
\hline Quintile 2 & 0.010 & 0.001 to 0.020 & 0.010 & 0.000 to 0.019 & 0.011 & 0.001 to 0.021 \\
\hline Quintile 3 & 0.009 & 0.000 to 0.018 & 0.009 & 0.000 to 0.018 & 0.009 & 0.000 to 0.017 \\
\hline Quintile 4 & 0.010 & 0.000 to 0.019 & 0.009 & 0.000 to 0.018 & 0.011 & 0.001 to 0.021 \\
\hline Quintile 5 & 0.011 & 0.000 to 0.021 & 0.011 & 0.001 to 0.022 & 0.009 & 0.000 to 0.018 \\
\hline $\mathrm{p}$ for trend & 0.9396 & & 0.1547 & & 0.0426 & \\
\hline \multicolumn{7}{|c|}{ Overweight } \\
\hline Quintile 1 & 0.012 & 0.001 to 0.024 & 0.014 & 0.001 to 0.028 & 0.013 & 0.001 to 0.026 \\
\hline Quintile 2 & 0.013 & 0.007 to 0.025 & 0.012 & 0.001 to 0.024 & 0.012 & 0.001 to 0.023 \\
\hline Quintile 3 & 0.012 & 0.001 to 0.023 & 0.014 & 0.001 to 0.026 & 0.012 & 0.001 to 0.024 \\
\hline Quintile 4 & 0.009 & 0.000 to 0.018 & 0.011 & 0.000 to 0.021 & 0.010 & 0.000 to 0.019 \\
\hline Quintile 5 & 0.011 & 0.000 to 0.022 & 0.010 & 0.000 to 0.019 & 0.011 & 0.000 to 0.022 \\
\hline $\mathrm{p}$ for trend & 0.1391 & & 0.0015 & & 0.0242 & \\
\hline \multicolumn{7}{|c|}{ Obese } \\
\hline Quintile 1 & 0.013 & 0.001 to 0.024 & 0.015 & 0.001 to 0.030 & 0.014 & 0.001 to 0.028 \\
\hline Quintile 2 & 0.018 & 0.001 to 0.034 & 0.013 & 0.001 to 0.026 & 0.015 & 0.001 to 0.030 \\
\hline Quintile 3 & 0.012 & 0.001 to 0.023 & 0.014 & 0.001 to 0.028 & 0.012 & 0.000 to 0.024 \\
\hline Quintile 4 & 0.013 & 0.000 to 0.025 & 0.013 & 0.001 to 0.026 & 0.012 & 0.000 to 0.023 \\
\hline Quintile 5 & 0.014 & 0.000 to 0.027 & 0.011 & 0.000 to 0.023 & 0.013 & 0.000 to 0.025 \\
\hline$p$ for trend & 0.5725 & & 0.0370 & & 0.0399 & \\
\hline
\end{tabular}

Probabilities are based on a Cox model that adjusts for age, gender, race/ethnicity, education, smoking, physical activity and energy intake. Models include interaction terms for baseline dietary scores and weight category. Separate models were developed for each dietary pattern. Weight categories were based on BMI (normal: $18.5-<25 \mathrm{~kg} / \mathrm{m}^{2}$; overweight: $25-<30 \mathrm{~kg} / \mathrm{m}^{2}$; obese: $\geq 30 \mathrm{~kg} / \mathrm{m}^{2}$ ).

$\mathrm{p}$ Values for interaction terms for quintiles of Mediterranean Diet and weight category are: Q2-overweight, 0.524; Q2-obese, 0.024; Q3overweight, 0.651; Q3-obese, 0.826; Q4-overweight, 0.354; Q4-obsese, 0.660; Q5-overweight, 0.547; Q5-obese, 0.881. p Values for interaction terms for quintiles of Healthy Eating Index and weight category are: Q2-overweight, 0.554; Q2-obese, 0.664; Q3-overweight, 0.154; Q3-obese, 0.290; Q4-overweight, 0.880; Q4-obsese, 0.542; Q5-overweight, 0.156; Q5-obese, 0.358. $p$ Values for interaction terms for quintiles of DASH and weight category are: Q2-overweight, 0.902; Q2-obese, 0.328; Q3-overweight, 0.254; Q3-obese, 0.530; Q4-overweight, 0.256; Q4-obsese, 0.525; Q5-overweight, 0.866; Q5-obese, 0.714

Our study has some limitations. We did not have information on family history of CRC, although the impact of family history is likely small given the age of the cohort. ${ }^{45}$ Medical comorbidity was not included as a covariate in the multivariable models. Our study population was relatively homogenous with upper-to-middle class Americans in urban centres: non-whites comprised a relatively small proportion of our sample. Dietary intake was self-reported and assessed using a single baseline Food Frequency Questionnaire, thus, there is potential for non-differential measurement error. ${ }^{46}$ With only a single measure, we could not examine changes in dietary intake over time. It is possible that the observed differences between men and women are artifacts from how the data were collected. For example, it has been suggested that differential bias could be introduced by the way women and men complete the Food Frequency Questionnaire. ${ }^{46} 47$ Women in the AARP (as a group) may have more variation in diet patterns and perception of dietary intake (and weight status) over time than men. ${ }^{25}$ Additionally, there is evidence that difference in dietary patterns may vary for men and women who respond in a similar manner to the same survey. ${ }^{13}$ Over $90 \%$ of the sample was non-Hispanic white. The research consistently shows that incident rates of CRC and obesity prevalence are higher in African Americans compared with whites. ${ }^{48} 49$ Although our sample was drawn from a nationally representative sample, it is not representative of adults in that age group because individuals from low socioeconomic status were not included. This is important because despite steady improvements in healthy eating patterns among US adults, the overall dietary quality remains poor particularly in low-income populations. $^{50} 51$ 
This is a large US national study with a prospective design of 398458 middle-aged and older adults with careful ascertainment of cancer outcome and detailed exposure measure using a well-validated Food Frequency Questionnaire. We used three indices of dietary patterns to assess association of high-quality diet with outcomes rather than individuals dietary components. The cohort was followed up over a subsequent 10-year period.

\section{CONCLUSION}

This longitudinal national study of 398458 middle-aged and older adults found that among normal-weight and overweight men, CRC risk was 25\%-30\% lower with high adherence to each dietary measure. Health benefits of consuming a high-quality diet extend to normal weight men, offering potential insights about approaches to cancer prevention. Additional research is needed to understand the weaker and less consistent results for women.

\section{Author affiliations}

${ }^{1}$ Department of Sociology, Clark University, Worcester, Massachusetts, USA ${ }^{2}$ Department of Psychiatry, Systems and Psychosocial Advances Research Center (SPARC), University of Massachusetts Medical School, Shrewsbury, Massachusetts, USA

${ }^{3}$ Department of Quantitative Health Sciences, University of Massachusetts Medical School, Worcester, Massachusetts, USA

${ }^{4}$ Department of Medicine, University of Massachusetts Medical School, Worcester, Massachusetts, USA

${ }^{5}$ Department of Family Medicine and Community Health, and the Center for Clinical Epidemiology and Biostatistics, Perelman School of Medicine, University of Pennsylvania, Philadelphia, Pennsylvania, USA

Acknowledgements This research was supported (in part) by the Intramural Research Program of the NIH, National Cancer Institute. Cancer incidence data from the Atlanta metropolitan area were collected by the Georgia Center for Cancer Statistics, Department of Epidemiology, Rollins School of Public Health, Emory University, Atlanta, Georgia. Cancer incidence data from California were collected by the California Cancer Registry, California Department of Public Health's Cancer Surveillance and Research Branch, Sacramento, California. Cancer incidence data from the Detroit metropolitan area were collected by the Michigan Cancer Surveillance Program, Community Health Administration, Lansing, Michigan. The Florida cancer incidence data used in this report were collected by the Florida Cancer Data System (Miami, Florida) under contract with the Florida Department of Health, Tallahassee, Florida. The views expressed herein are solely those of the authors and do not necessarily reflect those of the FCDC or FDOH. Cancer incidence data from Louisiana were collected by the Louisiana Tumor Registry, Louisiana State University Health Sciences Center School of Public Health, New Orleans, Louisiana. Cancer incidence data from New Jersey were collected by the New Jersey State Cancer Registry, The Rutgers Cancer Institute of New Jersey, New Brunswick, New Jersey. Cancer incidence data from North Carolina were collected by the North Carolina Central Cancer Registry, Raleigh, North Carolina. Cancer incidence data from Pennsylvania were supplied by the Division of Health Statistics and Research, Pennsylvania Department of Health, Harrisburg, Pennsylvania. The Pennsylvania Department of Health specifically disclaims responsibility for any analyses, interpretations or conclusions. Cancer incidence data from Arizona were collected by the Arizona Cancer Registry, Division of Public Health Services, Arizona Department of Health Services, Phoenix, Arizona. Cancer incidence data from Texas were collected by the Texas Cancer Registry, Cancer Epidemiology and Surveillance Branch, Texas Department of State Health Services, Austin, Texas. Cancer incidence data from Nevada were collected by the Nevada Central Cancer Registry, Division of Public and Behavioral Health, State of Nevada Department of Health and Human Services, Carson City, Nevada.We are indebted to the participants in the $\mathrm{NIH}-\mathrm{AARP}$ Diet and Health Study for their outstanding cooperation. We also thank Sigurd Hermansen and Kerry Grace Morrissey from Westat for study outcomes ascertainment and management and Leslie Carroll at Information Management
Services for data support and analysis. The authors want to gratefully acknowledge and thank Drs. Rachel Ballard-Barbash and Jill Reedy for their invaluable feedback on the manuscript.

Contributors All authors approved the final version of the manuscript. RATS drafted the original manuscript and interpreted the findings; CAD conceived of the study and participated in the analyses and interpretation of the data. JA and MEW conducted the analyses and interpreted the data. SLC and CIK contributed to the interpretation of the findings and critically revised the manuscript. RATS agrees to be accountable for all aspects of the work in ensuring that questions related to the accuracy or integrity of any part of the work are appropriately investigated and resolved.

Funding The content of this manuscript was developed with funding from the National Cancer Institute at the National Institutes of Health (U01-CA1517361, PI: Doubeni). The contents of this manuscript do not necessarily reflect the views of the funding agencies and you should not assume endorsement by the Federal Government. Research reported in this publication was supported by the National Institute of Minority Health and Health Disparities of the National Institutes of Health under Award Number P60MD006912 (PI: Allison). The content is solely the responsibility of the authors and does not necessarily represent the official views of the National Institutes of Health. Partial support for Dr Waring provided by NIH grants KL2TR000160 and U01HL105268. Dr Cutrona was supported by the National Center for Advancing Translational Sciences of the National Institutes of Health under award number KL2TR000160. The content is solely the responsibility of the authors and does not necessarily represent the official views of the NIH.

Competing interests None declared.

Patient consent Deidentified data.

Provenance and peer review Not commissioned; externally peer reviewed.

Data sharing statement Extra data is available by submitting a proposal for each project/manuscript for review by the NIH AARP Steering Committee prior to accessing NIH AARP data and to developing an associated manuscript. A proposal must be submitted through the public website, NIH-AARP Diet \& Health Study Tracking and Review System (STaRS, https://www.nihaarpstars.com).

Open Access This is an Open Access article distributed in accordance with the Creative Commons Attribution Non Commercial (CC BY-NC 4.0) license, which permits others to distribute, remix, adapt, build upon this work non-commercially, and license their derivative works on different terms, provided the original work is properly cited and the use is non-commercial. See: http://creativecommons.org/ licenses/by-nc/4.0/

(c) Article author(s) (or their employer(s) unless otherwise stated in the text of the article) 2017. All rights reserved. No commercial use is permitted unless otherwise expressly granted.

\section{REFERENCES}

1. Siegel RL, Miller KD, Jemal A. Cancer statistics, 2016. CA Cancer J Clin 2016;66:7-30.

2. Huxley RR, Ansary-Moghaddam A, Clifton P, et al. The impact of dietary and lifestyle risk factors on risk of colorectal cancer: a quantitative overview of the epidemiological evidence. Int $J$ Cancer 2009;125:171-80.

3. Stoneham M, Goldacre M, Seagroatt V, et al. Olive oil, diet and colorectal cancer: an ecological study and a hypothesis. $J$ Epidemiol Community Health 2000;54:756-60.

4. Kontou N, Psaltopoulou T, Soupos N, et al. The mediating effect of Mediterranean diet on the relation between smoking and colorectal cancer: a case-control study. Eur J Public Health 2013;23:742-6.

5. Fuchs CS, Giovannucci EL, Colditz GA, et al. Dietary fiber and the risk of colorectal cancer and adenoma in women. $N$ Engl J Med 1999;340:169-76.

6. Park Y, Hunter DJ, Spiegelman D, et al. Dietary fiber intake and risk of colorectal cancer: a pooled analysis of prospective cohort studies. JAMA 2005;294:2849-57.

7. Aune D, Chan DS, Lau R, et al. Dietary fibre, whole grains, and risk of colorectal cancer: systematic review and dose-response metaanalysis of prospective studies. BMJ 2011;343:d6617.

8. Doubeni CA, Major JM, Laiyemo AO, et al. Contribution of behavioral risk factors and obesity to socioeconomic differences in colorectal cancer incidence. J Natl Cancer Inst 2012;104:1353-62.

9. Larsson SC, Wolk A. Obesity and colon and rectal cancer risk: a meta-analysis of prospective studies. Am J Clin Nutr 2007;86:556-65. 
10. Moghaddam AA, Woodward M, Huxley R. Obesity and risk of colorectal cancer: a meta-analysis of 31 studies with 70,000 events. Cancer Epidemiol Biomarkers Prev 2007;16:2533-47.

11. Howard RA, Freedman DM, Park Y, et al. Physical activity, sedentary behavior, and the risk of colon and rectal cancer in the NIH-AARP Diet and Health Study. Cancer Causes Control 2008;19:939-53.

12. Siegel EM, Ulrich CM, Poole EM, et al. The effects of obesity and obesity-related conditions on colorectal cancer prognosis. Cancer Control 2010;17:52-7.

13. Reedy J, Mitrou PN, Krebs-Smith SM, et al. Index-based dietary patterns and risk of colorectal cancer: the NIH-AARP Diet and Health Study. Am J Epidemiol 2008;168:38-48.

14. Bamia C, Lagiou P, Buckland G, et al. Mediterranean diet and colorectal cancer risk: results from a European cohort. Eur $J$ Epidemiol 2013;28:317-28.

15. Lee DH, Keum N, Giovannucci EL. Colorectal cancer epidemiology in the nurses' Health Study. Am J Public Health 2016;106:1599-607.

16. Pignone M, Rich M, Teutsch SM, et al. Screening for colorectal cancer in adults at average risk: a summary of the evidence for the U.S. Preventive Services Task Force. Ann Intern Med 2002:137:132-41.

17. Lebwohl B, Capiak K, Neugut Al, et al. Risk of colorectal adenomas and advanced neoplasia in Hispanic, black and white patients undergoing screening colonoscopy. Aliment Pharmacol Ther 2012;35:1467-73.

18. Platz EA, Willett WC, Colditz GA, et al. Proportion of colon cancer risk that might be preventable in a cohort of middle-aged US men. Cancer Causes Control 2000;11:579-88.

19. Ogden CL, Carroll MD, Kit BK, et al. Prevalence of childhood and adult obesity in the United States, 2011-2012. JAMA 2014;311:806-14.

20. Amine E, Baba N, Belhadj M, et al. Diet, Nutrition and the Prevention of Chronic Diseases: Report of a Joint WHO/FAO Expert Consultation: World Health Organization. 2002

21. Sacks FM, Obarzanek E, Windhauser MM, et al. Rationale and design of the Dietary Approaches to stop hypertension trial (DASH) A multicenter controlled-feeding study of dietary patterns to lower blood pressure. Ann Epidemiol 1995;5:108-18.

22. Karanja NM, Obarzanek E, Lin PH, et al. Descriptive characteristics of the dietary patterns used in the Dietary Approaches to stop hypertension trial. DASH Collaborative Research Group. J Am Diet Assoc 1999;99:S19-S27.

23. Knoops KT, de Groot LC, Kromhout D, et al. Mediterranean diet, lifestyle factors, and 10-year mortality in elderly european men and women: the HALE project. JAMA 2004;292:1433-9.

24. Jensen MD, Ryan DH, Apovian CM, et al. 2013 AHA/ACC/TOS guideline for the management of overweight and obesity in adults: a report of the American College of Cardiology/American Heart Association Task Force on Practice guidelines and the Obesity Society. J Am Coll Cardiol 2014;63.

25. Schatzkin A, Subar AF, Thompson FE, et al. Design and serendipity in establishing a large cohort with wide dietary intake distributions : the National Institutes of Health-American Association of Retired Persons Diet and Health Study. Am J Epidemiol 2001;154:1119-25.

26. Thompson FE, Subar AF, Brown CC, et al. Cognitive research enhances accuracy of food frequency questionnaire reports: results of an experimental validation study. J Am Diet Assoc 2002;102:212-25.

27. Thompson FE, Kipnis V, Midthune D, et al. Performance of a foodfrequency questionnaire in the US NIH-AARP (National Institutes of Health-American Association of Retired Persons) Diet and Health Study. Public Health Nutr 2008;11:183-95

28. Guenther PM, Kirkpatrick SI, Reedy J, et al. The Healthy Eating Index-2010 is a valid and reliable measure of diet quality according to the 2010 Dietary guidelines for Americans. J Nutr 2014;144:399-407.
29. Fung TT, Hu FB, McCullough ML, et al. Diet quality is associated with the risk of estrogen receptor-negative breast cancer in postmenopausal women. J Nutr 2006;136:466-72.

30. Reedy J, Krebs-Smith SM, Miller PE, et al. Higher diet quality is associated with decreased risk of all-cause, cardiovascular disease, and cancer mortality among older adults. J Nutr 2014;144:881-9.

31. Mitrou PN, Kipnis V, Thiébaut AC, et al. Mediterranean dietary pattern and prediction of all-cause mortality in a US population: results from the NIH-AARP Diet and Health Study. Arch Intern Med 2007:167:2461-8.

32. Appel LJ, Moore TJ, Obarzanek E, et al. A clinical trial of the effects of Dietary patterns on blood pressure. N Engl J Med Overseas Ed 1997:336:1117-24

33. $\mathrm{Xu} \mathrm{J}$, Long S. Confidence intervals for predicted outcomes in regression models for categorical outcomes. The Stata Journal 2005;5:537-59.

34. Cleves M, Gould W, Gutierrez RG, et al. An introduction to Survival Analysis using Stata. Third Edition. College Station, TX: Stata Press, 2010

35. Miller PE, Lesko SM, Muscat JE, et al. Dietary patterns and colorectal adenoma and cancer risk: a review of the epidemiological evidence. Nutr Cancer 2010;62:413-24.

36. Miller PE, Cross AJ, Subar AF, et al. Comparison of 4 established DASH diet indexes: examining associations of index scores and colorectal cancer. Am J Clin Nutr 2013;98:794-803.

37. Sandhu MS, Dunger DB, Insulin GEL, et al. IGF-I), IGF binding proteins, their biologic interactions, and colorectal cancer. Journal of the National Cancer Institute 2002;94:972-80.

38. Pereira MA, Jacobs DR, Van Horn L, et al. Dairy consumption, obesity, and the insulin resistance syndrome in young adults: the CARDIA Study. JAMA 2002;287:2081-9.

39. Jacobs ET, Thompson PA, Martínez ME. Diet, gender, and colorectal neoplasia. J Clin Gastroenterol 2007;41:731-46.

40. Grodstein F, Newcomb PA, Stampfer MJ. Postmenopausal hormone therapy and the risk of colorectal cancer: a review and meta-analysis Am J Med 1999;106:574-82.

41. Mørch LS, Lidegaard Ø, Keiding N, et al. The influence of hormone therapies on colon and rectal cancer. Eur J Epidemiol 2016;31:481-9.

42. Dai Z, Xu YC, Niu L. Obesity and colorectal cancer risk: a metaanalysis of cohort studies. World J Gastroenterol 2007;13:4199.

43. David LA, Maurice CF, Carmody RN, et al. Diet rapidly and reproducibly alters the human gut microbiome. Nature 2014;505:559-63.

44. Turnbaugh PJ, Hamady M, Yatsunenko T, et al. A core gut microbiome in obese and lean twins. Nature 2009;457:480-4.

45. Doubeni CA, Fletcher RH. Family history of colorectal cancer: it is time to rethink screening recommendations. Gastroenterology 2015; 149:1321-2.

46. Subar AF, Kipnis V, Troiano RP, et al. Using intake biomarkers to evaluate the extent of dietary misreporting in a large sample of adults: the OPEN study. Am J Epidemiol 2003;158:1-13.

47. Kipnis V, Subar AF, Midthune D, et al. Structure of dietary measurement error: results of the OPEN biomarker study. Am J Epidemiol 2003;158:14-21.

48. Ward E, Jemal A, Cokkinides V, et al. Cancer disparities by race/ethnicity and socioeconomic status. CA Cancer J Clin 2004;54:78-93.

49. Irby K, Anderson WF, Henson DE, et al. Emerging and widening colorectal carcinoma disparities between Blacks and Whites in the United States (1975-2002). Cancer Epidemiol Biomarkers Prev 2006;15:792-7.

50. Wang DD, Leung CW, Li Y, et al. Trends in dietary quality among adults in the United States, 1999 through 2010. JAMA Intern Med 2014; 174:1587-95.

51. Krebs-Smith SM, Guenther PM, Subar AF, et al. Americans do not meet federal dietary recommendations. J Nutr 2010;140:1832-8. 